Cite this: RSC Adv., 2019, 9, 31828

Received 8th July 2019

Accepted 17th September 2019

DOI: 10.1039/c9ra05172d

rsc.li/rsc-advances
Check for updates

\section{A noble bimetal oxysulfide CuVOS catalyst for highly efficient catalytic reduction of 4-nitrophenol and organic dyes}

\author{
Huizhi Sun, ${ }^{a}$ Osman Ahmed Zelekew, (D) *b Xiaoyun Chen, (D) *a Yuanbo Guo, ${ }^{a}$ \\ Dong-Hau Kuo, (D) *c Qingxin Lu and Jinguo Lin ${ }^{\star a}$
}

\begin{abstract}
A novel copper-vanadium bimetallic oxysulfide (CuVOS) nanoparticle catalyst was successfully synthesized by a facile method. The samples were characterized by X-ray photoelectron spectrometry (XPS), X-ray diffractometry (XRD), field-emission scanning electron microscopy (FE-SEM), UV-Vis diffuse spectroscopy (DRS), Fourier transform infrared spectroscopy (FTIR), and $\mathrm{N}_{2}$ adsorption-desorption isotherms. In order to check the catalytic efficiencies toward reduction reaction, 4-nitrophenol (4-NP) and other organic dyes such as rhodamine-B (RhB), methylene blue (MB), and methyl orange (MO) were used. The results showed that the CuVOS prepared in the presence of a suitable amount of $\mathrm{N}_{2} \mathrm{H}_{4}$ during the synthesis of the nanoparticles exhibited the fastest reduction capabilities by using $\mathrm{NaBH}_{4}$ as a reducing agent. It was demonstrated that a $100 \mathrm{~mL} 4-\mathrm{NP}(20 \mathrm{ppm})$ solution was completely reduced by $5 \mathrm{mg}$ CuVOS-3 within $2 \mathrm{~min}$. Moreover, the complete reduction of $100 \mathrm{~mL}$ of $\mathrm{MO}$, RhB, and MB solutions of 100 ppm was also achieved by $5 \mathrm{mg} \mathrm{CuVOS-3}$ within $2 \mathrm{~min}, 6 \mathrm{~min}$, and $5 \mathrm{~min}$, respectively. Hence, the CuVOS is an efficient catalyst for reducing 4-NP and organic dyes and can have great potential for industrial application.
\end{abstract}

\section{Introduction}

Recently, the rapid growth of population and industry became the major concern regarding environmental and energy issues. ${ }^{1}$ In particular, the discharge of toxic nitroaromatic organic compounds used in the manufacturing of pharmaceuticals, pigments, explosives, plastics, pesticides and fungicidal agents is potentially dangerous to humans and the environment. ${ }^{2-4}$ Among the nitroaromatic compounds, 4-nitrophenol (4-NP) and its derivatives are the most toxic and can be the cause for the damage of the central nervous system, kidney, liver and human blood., ${ }^{5,6}$ In addition to nitroaromatic compounds, synthetic dyes discharged from different industries such as paper and pulp manufacturing, leather industries, cloth dyeing, and plastics coloring have been used extensively and are also a source of environmental pollution. ${ }^{6-8}$ Particularly, strong color and pigment dyes discharged into the aquatic system cause serious environmental problems and are also the major

${ }^{a}$ College of Materials Engineering, Fujian Agriculture \& Forestry University, Fuzhou 350002, China.E-mail: fjchenxy@126.com; fjlinjg@126.com

${ }^{b}$ Department of Materials Science and Engineering, Adama Science and Technology University, Adama, Ethiopia.E-mail: osman.ahmed@astu.edu.et

'Department of Materials Science and Engineering, National Taiwan University of Science and Technology, No. 43, Sec. 4, Keelung Road, Taipei 10607, Taiwan. E-mail:dhkuo@mail.ntust.edu.tw concern for water pollution. ${ }^{\mathbf{9 - 1 2}}$ Hence the reduction and removal of toxic organic compounds from aquatic environments is a crucial mission.

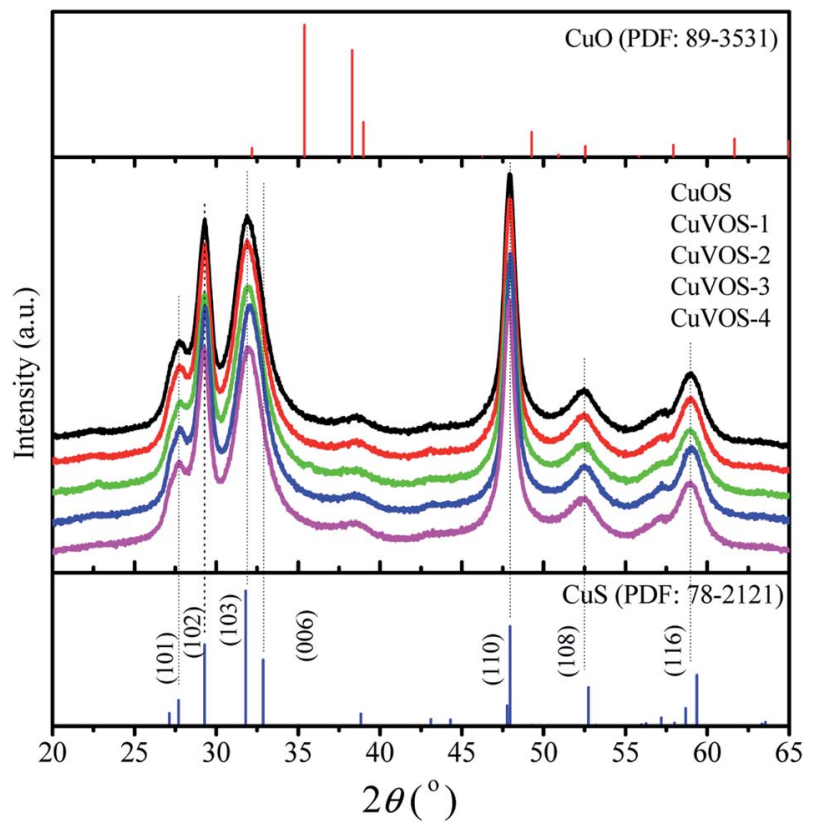

Fig. 1 XRD diffraction patterns of CuVOS catalysts with different amounts of hydrazine. 
Table 1 XPS composition analyses of CuVOS catalysts

\begin{tabular}{|c|c|c|c|c|c|c|c|c|c|c|c|c|c|}
\hline \multirow[b]{2}{*}{ Catalyst } & \multicolumn{4}{|c|}{ Molar percentage (\%) } & \multicolumn{2}{|c|}{$\begin{array}{l}\mathrm{Cu} \text { molar } \\
\text { percentage } \\
(\%)\end{array}$} & \multirow{2}{*}{$\begin{array}{l}\mathrm{Cu}^{+} / \mathrm{Cu}^{2+} \text { molar } \\
\text { ratio }\end{array}$} & \multicolumn{2}{|c|}{$\begin{array}{l}\text { O molar } \\
\text { percentage } \\
(\%)\end{array}$} & \multicolumn{2}{|c|}{$\begin{array}{l}\text { S molar } \\
\text { percentage } \\
(\%)\end{array}$} & \multirow{2}{*}{$\begin{array}{l}\mathrm{S}^{2-} / \mathrm{S}^{6+} \text { molar } \\
\text { ratio }\end{array}$} & \multirow{2}{*}{$\begin{array}{l}\text { Crystal sizes } \\
(\mathrm{nm})\end{array}$} \\
\hline & $\mathrm{Cu}$ & $\mathrm{V}$ & $\mathrm{O}$ & $\mathrm{S}$ & $\mathrm{Cu}(\mathrm{I})$ & $\mathrm{Cu}(\mathrm{II})$ & & $\mathrm{O}-\mathrm{H}$ & $\mathrm{O}_{\text {lattice }}$ & $\mathrm{S}^{2-}$ & $S^{6+}$ & & \\
\hline CuVOS-1 & 35.65 & 2.69 & 21.03 & 40.67 & 65.49 & 34.51 & 1.90 & 29.96 & 70.04 & 88.93 & 11.07 & 8.03 & 12.7 \\
\hline CuVOS-2 & 35.37 & 2.71 & 21.27 & 40.65 & 69.33 & 30.67 & 2.26 & 30.84 & 69.16 & 87.22 & 12.78 & 6.82 & 13.2 \\
\hline CuVOS-3 & 35.26 & 2.72 & 21.15 & 40.87 & 72.02 & 27.98 & 2.57 & 30.73 & 69.27 & 85.65 & 14.35 & 5.97 & 13.5 \\
\hline $\mathrm{Cu} V \mathrm{OS}-4$ & 35.62 & 2.68 & 20.98 & 40.72 & 75.31 & 24.69 & 3.05 & 30.50 & 69.50 & 84.16 & 15.84 & 5.31 & 13.1 \\
\hline CuS commercial & 48.91 & 0 & 2.41 & 48.68 & 0 & 100 & - & - & - & - & - & - & - \\
\hline CuVOS-3 after reaction & 35.40 & 2.65 & 21.07 & 40.88 & 72.05 & 27.95 & 2.58 & 30.55 & 69.45 & 85.47 & 14.53 & 5.88 & - \\
\hline
\end{tabular}

In the recent years, many researchers have tried to remove toxic organic compounds and also decolorize wastewater by using different techniques. Among the methods used, photocatalytic degradation, adsorption, membrane flocculation, filtration, and reduction technological applications are reported by different scholars. ${ }^{13-19}$ Sun et al. used a carbon microsphereloaded copper-based catalyst for the degradation of organic dyes in aqueous solution. ${ }^{20}$ Liu et al. also studied the synthesis of various $\mathrm{NiCo}_{2} \mathrm{O}_{4}$ structures to degrade organic dyes under microwave catalysis. ${ }^{21}$ Zhao et al. studied the photocatalytic degradation of 4-nitrophenol in the presence of $\mathrm{H}_{2} \mathrm{O}_{2}$ in a UVirradiated water dispersion system using $\mathrm{TiO}_{2}$ catalyst doped with different amounts of iron, and systematically explored 1\% $\mathrm{Fe}-\mathrm{TiO}_{2}$ catalyst. ${ }^{22}$ Moreover, the catalytic reduction of 4-nitrophenol was also conducted by Zelekew et al. with silicasupported metal oxide-based catalysts. ${ }^{23,24}$ Elfiad et al. also used hematite to explore the conversion of nitrophenol (4-NP) to 4-aminophenols (4-AP). ${ }^{25}$ Ajmal et al. also reported the simultaneous catalytic degradation/reduction of multiple toxic organic compounds by modifiable $\mathrm{p}$ (methacrylic acid-co-acrylonitrile)-M ( $\mathrm{M}: \mathrm{Cu}, \mathrm{Co})$ microgel catalyst composites. ${ }^{26}$ The reduction of rhodamine $\mathrm{B}$ by using magnetically recyclable $\mathrm{Ag}-$ $\mathrm{Fe}_{3} \mathrm{O}_{4}$ composite catalyst haven also reported by Ai et al. ${ }^{27}$ However, the synthesis of the catalyst at low temperature
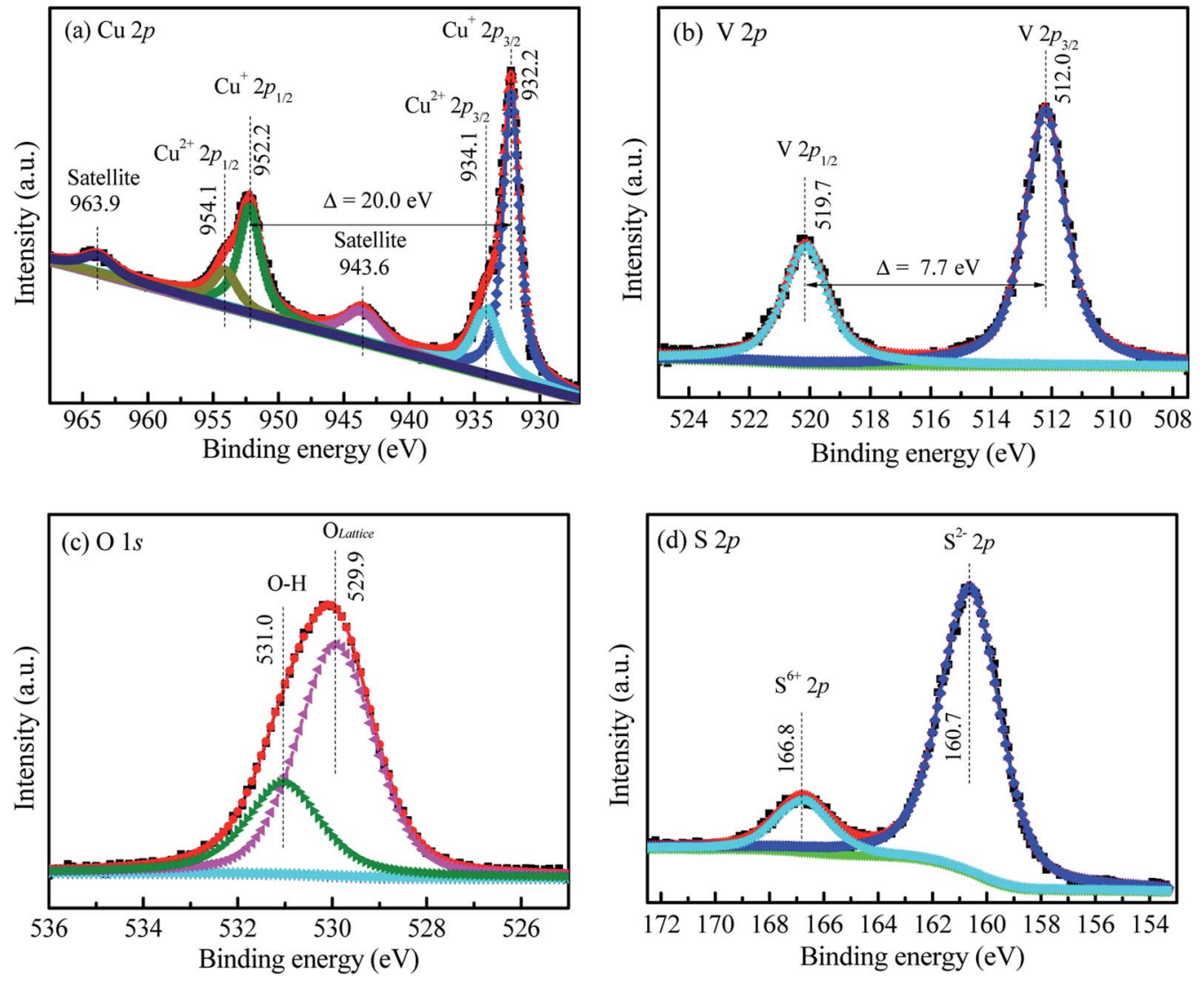

Fig. 2 High resolution (a) Cu 2p, (b) V 2p, (c) O 1s, and (d) S 2p XPS spectra of CuVOS-3. 
process with efficient and low-cost catalyst for wastewater treatment is still the biggest challenge. Therefore, the development of straight forward methods for preparing efficient catalysts at low temperature is mandatory. Moreover, the existence of bimetallic compound catalyst is expected to enhance the catalytic activities by the synergistic effect.
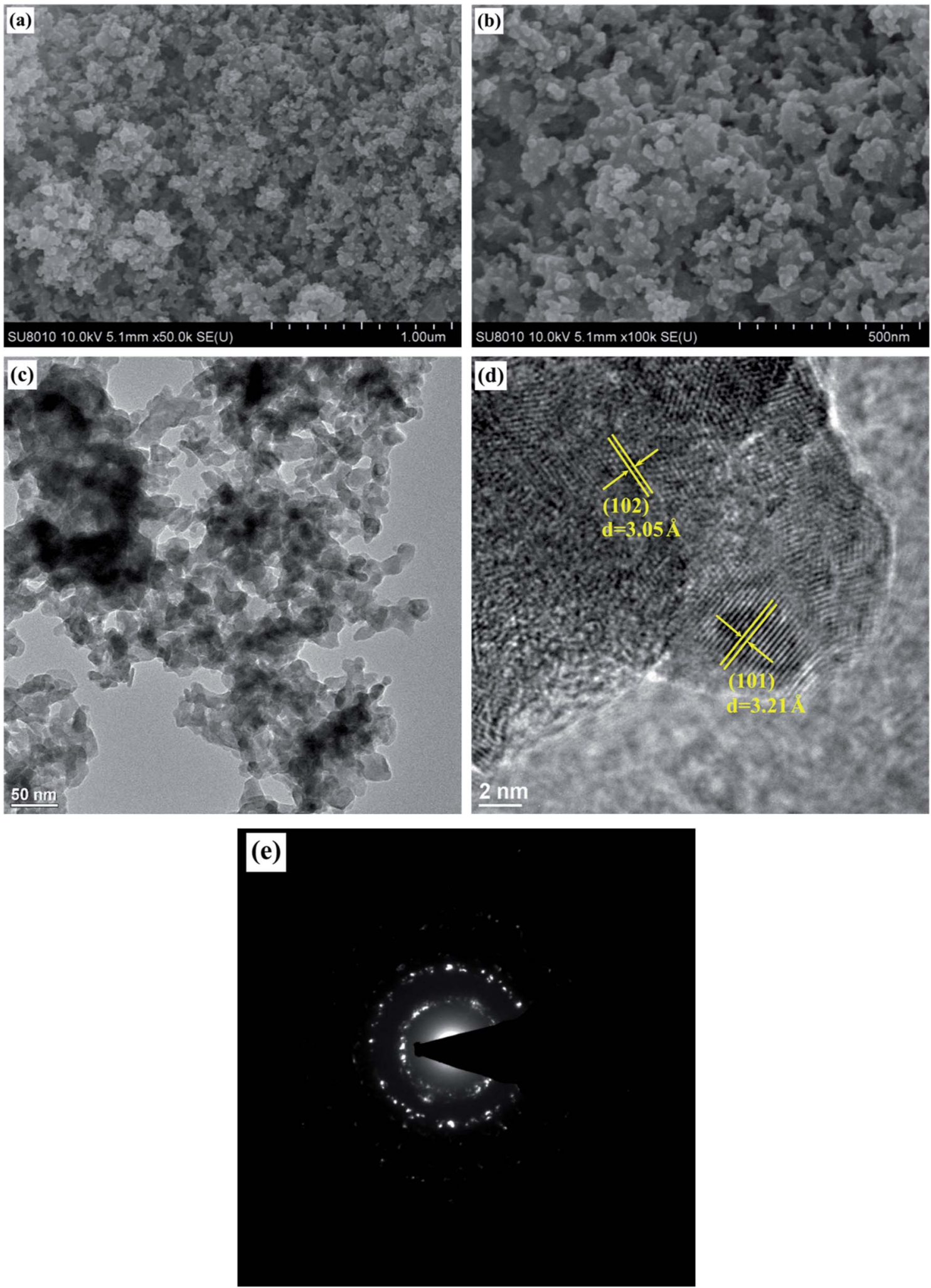

Fig. 3 (a and b) FE-SEM, (c) TEM, and (d) HR-TEM images, and (e) SAED pattern of CuVOS-3 catalyst. 

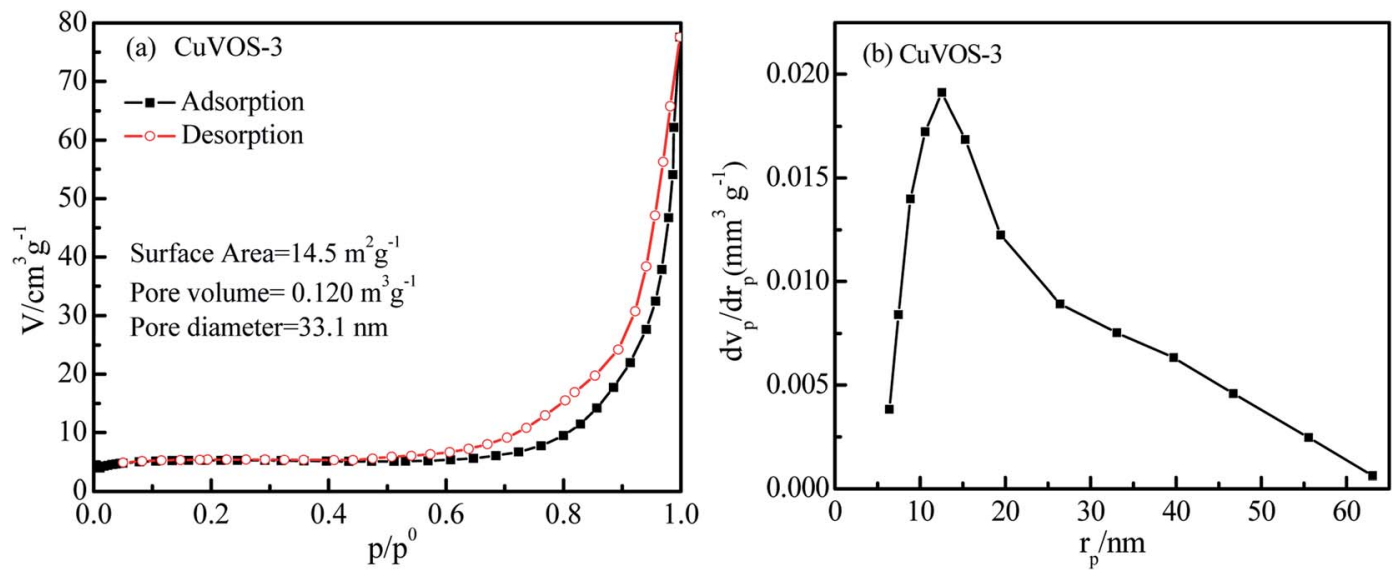

Fig. 4 (a) Nitrogen adsorption-desorption isotherm and (b) the pore size distribution curve of CuVOS-3.

In our previous work, the synthesis of the $\mathrm{Zn}(\mathrm{O}, \mathrm{S})$ oxysulfide has been used for hydrogen production. ${ }^{28}$ The copper-based oxysulfide bimetallic CuNiOS catalysts with the effect of the $\mathrm{Cu}^{+} / \mathrm{Cu}^{2+}$ ratio for chromium reduction was also reported by our group. However, there was no report on $\mathrm{CuVOS}$ bimetallic catalysts for the removal or reduction of organic compounds. This study aims to synthesize a copper-based bimetallic oxysulfide $\mathrm{CuVOS}$ catalyst for the catalytic reduction of toxic organic compounds. The catalytic performance of the catalyst is checked by the reduction of 4-NP and other organic dyes such as $\mathrm{MB}, \mathrm{MO}$, and RhB.

\section{Experimental}

\subsection{Synthesis of CuVOS}

In a particular procedure, $4.8 \mathrm{~g}$ of copper nitrate $\left[\mathrm{Cu}\left(\mathrm{NO}_{3}\right)_{2}-\right.$ $\left.\cdot 2.5 \mathrm{H}_{2} \mathrm{O}\right]$ and $1.0 \mathrm{~g}$ of ammonium metavanadate $\left(\mathrm{NH}_{4} \mathrm{VO}_{3}\right)$ were dissolved into $900 \mathrm{~mL}$ DI water under vigorously stirring. Then, $100 \mathrm{~mL} 0.3 \mathrm{~mol} \mathrm{~L}^{-1}$ thioacetamide $\left(\mathrm{CH}_{3} \mathrm{CSNH}_{2}, \mathrm{TAA}\right)$ was added into the solution drop by drop. After 30 minutes stirring at room temperature, the mixture was then heated to $90{ }^{\circ} \mathrm{C}$ and then $0.4 \mathrm{~mL}$ of hydrazine hydrate $\left(\mathrm{N}_{2} \mathrm{H}_{4}\right)$ was slowly dropped into the mixture followed with $2 \mathrm{~h}$ reaction. To optimize the amount of the added hydrazine, $0,0.2,0.4$, and $0.6 \mathrm{~mL}$ of hydrazine were added to form products labeled as CuVOS-1, CuVOS-2, CuVOS-3, and $\mathrm{Cu} V \mathrm{OS}-4$, respectively. Subsequently, the obtained precipitate was washed, centrifuged, and dried with rotary evaporation to obtain $\mathrm{CuVOS}$ catalysts prepared with different $\mathrm{N}_{2} \mathrm{H}_{4}$ contents. For comparison purpose, $\mathrm{CuOS}$ was prepared with the same procedure without the addition of vanadium source.

\subsection{Characterizations}

The XRD pattern of the CuOS and CuVOS catalysts was characterized by the Rigaku X-ray diffractometer with the $\mathrm{Cu} \mathrm{K} \alpha$ radiation $(\lambda=1.5406 \AA)$ sources. The XPS analysis was performed by the PHI5700 photoelectron spectrometer with $\mathrm{Al} \mathrm{K \alpha}$ X-ray $(h \nu=1486.6 \mathrm{eV})$ radiation, and C 1s at $284.62 \mathrm{eV}$ was used for calibration purpose. The FTIR analysis was performed by Agilent Digilab FTS-3500 Fourier transforms infrared spectrometer. The surface morphologies of the samples were checked by FE-SEM (HITACHI SU-8010 microscope) with an accelerating voltage of $10 \mathrm{kV}$ and by TEM and HR-TEM (Tecnai F20 G2 microscope). The UV-Vis DRS analysis was characterized by TU-1901 UV-Vis spectrophotometer equipped with an integrating sphere, and $\mathrm{BaSO}_{4}$ was as a reference.

\subsection{Catalytic reduction experiments}

2.3.1 Catalytic reduction of 4-NP. In the particular procedure, $5 \mathrm{mg} \mathrm{Cu}$ VOS catalyst was added into $100 \mathrm{~mL}\left(20 \mathrm{mg} \mathrm{L}^{-1}\right) 4$ $\mathrm{NP}$ aqueous solution. Then, freshly prepared, $3 \mathrm{~mL}\left(0.2 \mathrm{~mol} \mathrm{~L}^{-1}\right)$ of $\mathrm{NaBH}_{4}$ aqueous solution was added to the mixture. Subsequently, $2 \mathrm{~mL}$ sample was taken from the reactor at a regular interval of time. The reduction progress of the resulting 4-NP was monitored by TU-1901 UV-Vis spectrophotometer at room temperature. The Lambert-Beer law was used to calculate their concentration.

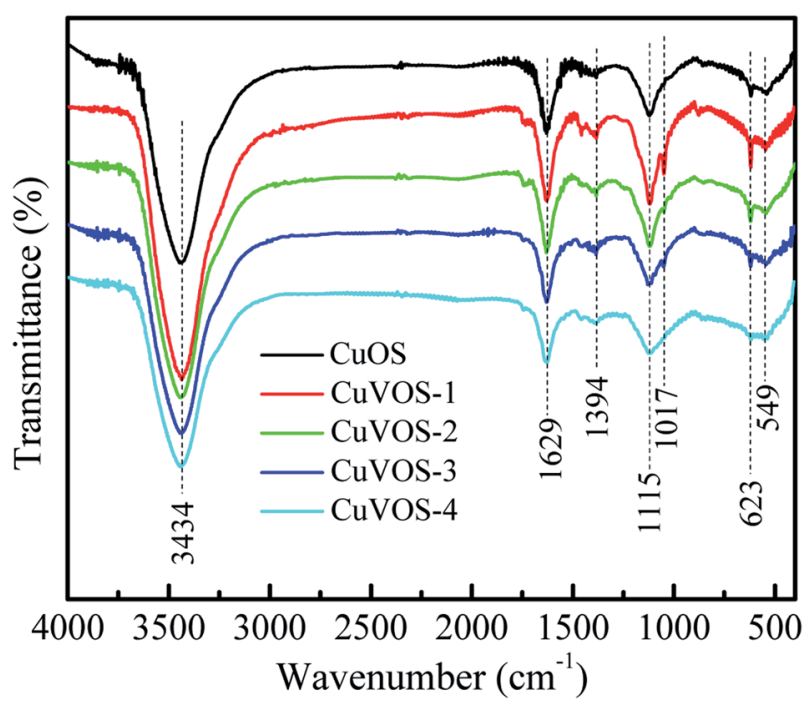

Fig. 5 FTIR spectra of CUOS and CuVOS prepared with different $\mathrm{N}_{2} \mathrm{H}_{4}$ contents. 
In the case of organic dye reduction, $\mathrm{MO}, \mathrm{MB}$, and $\mathrm{RhB}$ dyes were selected to test the catalytic performance of the samples. In a particular procedure, $5 \mathrm{mg}$ CuVOS catalyst was added into $100 \mathrm{~mL}$ (100 ppm) MO solution. Then, $3 \mathrm{~mL} 0.2 \mathrm{~mol} \mathrm{~L}^{-1} \mathrm{NaBH}_{4}$ solution was added to the above solution. Subsequently, $2 \mathrm{~mL}$ of sample was removed from the reactor at a regular interval time. For $\mathrm{MB}$ and $\mathrm{RhB}$ dyes, the concentration of the dye and the amount of $\mathrm{NaBH}_{4}$ used were similar with the reduction of $\mathrm{MO}$ dye mentioned above. According to the absorbance maxima of MO, $\mathrm{MB}$, and $\mathrm{RhB}$ at $465 \mathrm{~nm}, 663 \mathrm{~nm}$, and $554 \mathrm{~nm}$, respectively, the retained concentration was calculated with the Lambert-Beer law.

To evaluate the stability of the catalyst, the CuVOS-3 catalyst was taken and used repeatedly. In a particular procedure, $200 \mathrm{mg}$ of CuVOS-3 catalyst was added into $4000 \mathrm{~mL}\left(20 \mathrm{mg} \mathrm{L}^{-1}\right)$ 4-NP aqueous solution in to $5000 \mathrm{~mL}$ beaker. Then, freshly prepared, $120 \mathrm{~mL}\left(0.2 \mathrm{~mol} \mathrm{~L}^{-1}\right)$ of $\mathrm{NaBH}_{4}$ aqueous solution was added in to the mixture and reduction progress of the resulting 4-NP was then monitored by TU-1901 UV-Vis spectrophotometer. After reaction, the solution was settled by gravity and the upper layer solution was poured out. The remaining solution was separated with centrifuged and the catalyst was used for the next reactions. After five time runs, the catalyst was collected and dried with oven at $60{ }^{\circ} \mathrm{C}$ for $2 \mathrm{~h}$ and used for XPS and XRD analysis.

\section{Results and discussion}

\subsection{XRD analysis}

Fig. 1 shows the XRD diffraction patterns of CuVOS. The diffraction peaks positions of CuVOS were correspondent with the structure of hexagonal CuS covellite (PDF \#89-2531). The major peaks of the samples were located at $2 \theta$ value of $27.66^{\circ}$, $28.36^{\circ}, 29.62^{\circ}, 31.81^{\circ}, 32.72^{\circ}, 48.23^{\circ}$, and $52.75^{\circ}$, which were attributed to (100), (101), (102), (103), (006), (110), and (108) crystal planes, respectively. As we have seen from the XRD peaks, there was a little shift to lower angle as we compared from CuS standard peaks. Moreover, the XRD diffraction patterns had no second phases of $\mathrm{CuO}, \mathrm{Cu}_{2} \mathrm{O}, \mathrm{Cu}_{2} \mathrm{~S}, \mathrm{~V}_{2} \mathrm{O}_{5}$, and $\mathrm{V}_{2} \mathrm{~S}_{5}$, which indicated that the $\mathrm{Cu}$ VOS catalyst is a solid solution. The peak full width at half maxima indicated that a little effect of adding different amount of $\mathrm{N}_{2} \mathrm{H}_{4}$ was observed on the crystal structure and crystallinity. The average crystal sizes of CuVOS catalysts prepared with different amounts of $\mathrm{N}_{2} \mathrm{H}_{4}$ were also calculated by Scherrer formula and showed in Table 1. As it is
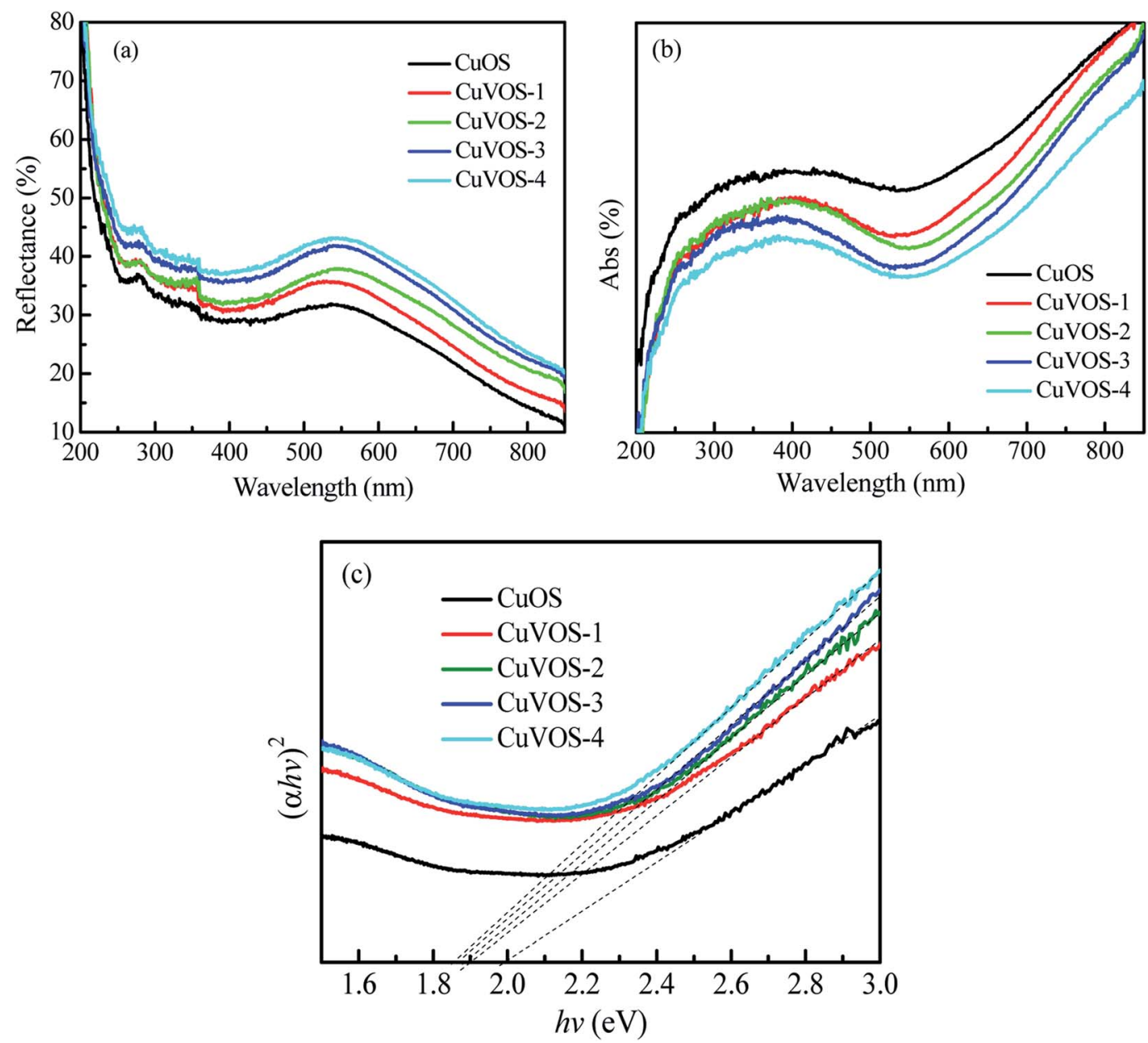

Fig. 6 Optical properties of CuOS and CuVOS series catalysts evaluating with (a) UV-Vis reflectance spectroscopy and (b) UV-Vis absorption spectroscopy. (c) The $(\alpha h \nu)^{2}-h \nu$ plot from the UV-Vis absorption measurements. 
observed from Table 1, the average the crystalline size for catalyst was $12.7-13.5 \mathrm{~nm}$.

\subsection{XPS analysis}

Fig. 2a also shows the $\mathrm{Cu} 2 \mathrm{p}$ XPS spectra of CuVOS-3. The peaks located at $932.22 \mathrm{eV}$ and $952.22 \mathrm{eV}$ represents for the $\mathrm{Cu} 2 \mathrm{p}_{3 / 2}$ and $\mathrm{Cu} 2 \mathrm{p}_{1 / 2}$, respectively, which indicates the presence of $\mathrm{Cu}(\mathrm{I})$ oxidation state in the sample. ${ }^{29}$ Moreover, the peaks for $\mathrm{Cu} 2 \mathrm{p}_{3 / 2}$ and $\mathrm{Cu} 2 \mathrm{p}_{1 / 2}$ located at $934.10 \mathrm{eV}$ and $954.10 \mathrm{eV}$, respectively, indicates the presence of $\mathrm{Cu}(\mathrm{II})$ oxidation state. ${ }^{30,31}$ The satellite peaks are also located at $943.7 \mathrm{eV}$ and $963.1 \mathrm{eV}$. The results indicated that the copper is existed in the forms of $\mathrm{Cu}(\mathrm{I})$ and $\mathrm{Cu}$ (II) oxidation states in the sample. ${ }^{30,31}$ Moreover, Fig. $2 \mathrm{~b}$ also shows the V 2p XPS spectra in the CuVOS-3 catalysts. The peaks of $\mathrm{V} 2 \mathrm{p}_{3 / 2}$ and $\mathrm{V} 2 \mathrm{p}_{1 / 2}$ located at $512.0 \mathrm{eV}$ and $519.7 \mathrm{eV}$, respectively, which indicates the existence of $\mathrm{V}(\mathrm{Iv})$ oxidation state in the CuVOS-3 sample. ${ }^{32}$ Fig. 2c shows the O 1s XPS spectra in the CuVOS-3 catalyst. The peaks at $531.0 \mathrm{eV}$ and
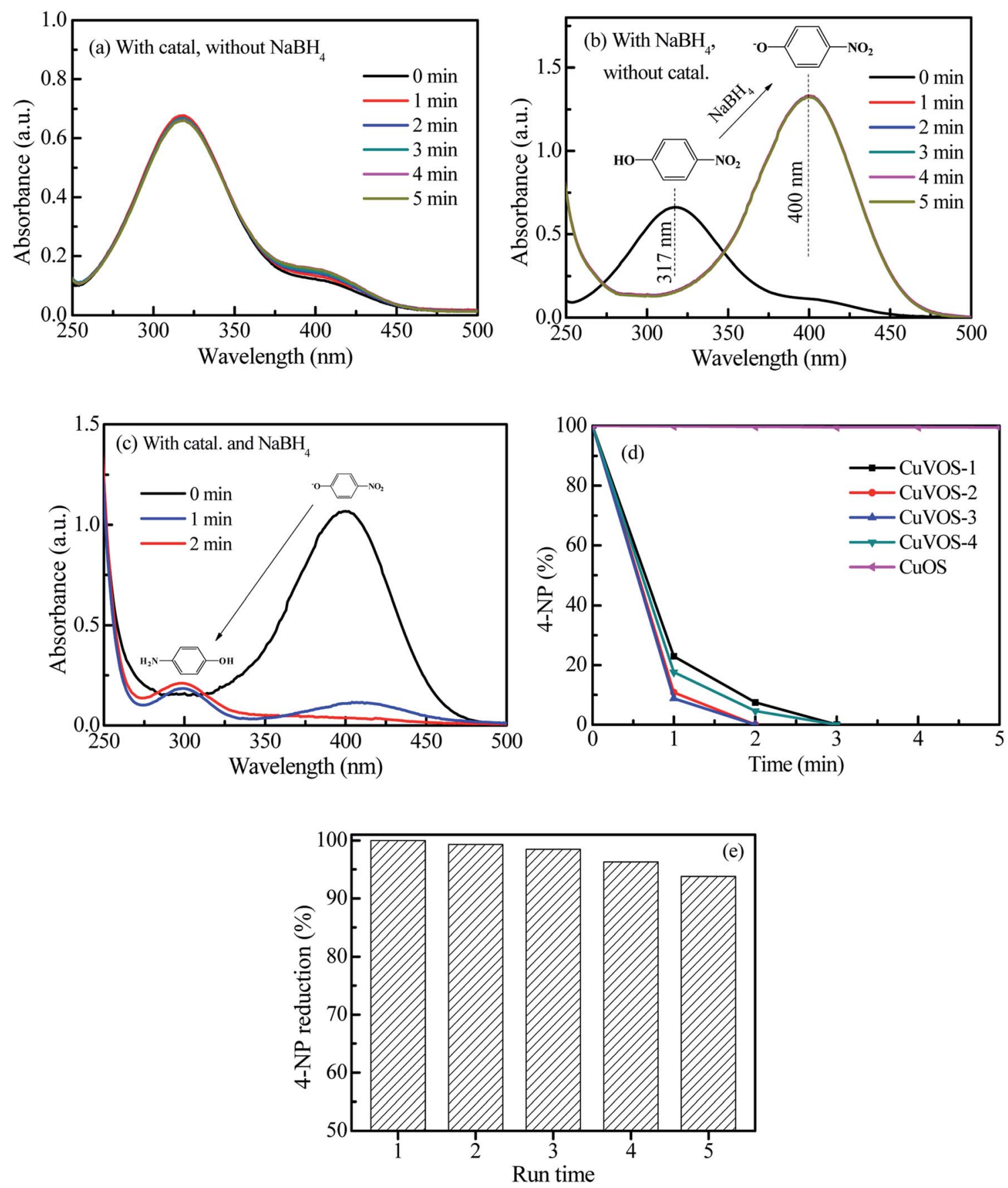

Fig. 7 (a) Reduction of 4-NP with CuVOS-3 catalyst without $\mathrm{NaBH}_{4}$, (b) reduction of 4-NP by $\mathrm{NaBH}_{4}$ without catalyst, (c) reduction of 4-NP by CuVOS-3 catalyst with $\mathrm{NaBH}_{4}$, (d) reduction of 4-NP by CuVOS catalyst prepared at different $\mathrm{N}_{2} \mathrm{H}_{4}$ contents with $\mathrm{NaBH}_{4}$, (e) the reusability of CuVOS-3 for 4-NP reduction. 
$529.9 \mathrm{eV}$ attributed to the hydroxyl oxygen and the lattice oxygen, respectively. ${ }^{33}$ The S 2p XPS spectra in the CuVOS-3 catalyst also showed in the Fig. $2 \mathrm{~d}$. The $\mathrm{S} 2 \mathrm{p}$ peaks at $160.7 \mathrm{eV}$ indicates the formation of $\mathrm{S}^{2-}$ and the peak at $166.8 \mathrm{eV}$ also showed the existence of $S^{6+}$ in the CuVOS-3 catalyst. ${ }^{34}$ Moreover, the chemical compositions of the CuVOS with different amount of hydrazine, and the CuVOS-3 catalyst after reused are shown on Table 1 according to the peak-fitting area. As it is indicated from Table 1, the molar ratios of $\mathrm{Cu}^{+} / \mathrm{Cu}^{2+}$ were increased as the amount of hydrazine increases due to the reduction of $\mathrm{Cu}^{2+}$ to $\mathrm{Cu}^{+}$. The $\mathrm{O}_{\text {lattice }}$ composition was almost constant with increasing hydrazine. However, the molar ratio of the $\mathrm{S}^{2-/} \mathrm{S}^{6+}$ decreases with increasing the amount of hydrazine.

\subsection{FE-SEM and TEM analyses}

Fig. 3a and b show the FE-SEM images of CuVOS-3 catalyst. As we checked the SEM images, the CuVOS nanoparticle and agglomeration with 50-200 $\mathrm{nm}$ were observed. Fig. 3c also indicates the TEM image of CuVOS-3 and it also further confirms the nanoparticle agglomeration. Fig. 3d displays the HR-TEM image of CuVOS-3 and the $d$-space values of $3.21 \AA$ and $3.05 \AA$ in the image were attributed to hexagonal CuS (101) and (102) planes, respectively. Fig. 3e also shows the selected area electron diffraction (SAED) pattern of CuVOS-3. The ring patterns illustrate its polycrystalline nature. In general, the XRD, XPS, and TEM analysis further confirms the formation of the major phase of CuS in the CuVOS solid solution.

\subsection{BET and pore size analysis}

Fig. 4a displays the $\mathrm{N}_{2}$ adsorption-desorption isotherm of CuVOS-3. As we can see from the Fig. 4a, it has a consistent trend with the type IV isotherm of the hysteresis loop for a mesoporous characteristics when the relative pressure $\left(P / P_{0}\right)$ is 0.75-1.0. ${ }^{35}$ Moreover, the pore size distribution curve of the samples is showed in Fig. $4 \mathrm{~b}$. The surface area $\left(S_{\mathrm{BET}}\right)$, total pore volume, and average pore diameter of CuVOS-3 were $14.5 \mathrm{~m}^{2}$ $\mathrm{g}^{-1}, 0.120 \mathrm{~m}^{3} \mathrm{~g}^{-1}$, and $33.1 \mathrm{~nm}$, respectively.

\subsection{FT-IR analysis}

Fig. 5 shows the FTIR spectra of CuOS and CuVOS prepared in the presence of different amounts of $\mathrm{N}_{2} \mathrm{H}_{4}$. The peaks located at
3434 and $1629 \mathrm{~cm}^{-1}$ corresponds to the vibration mode of the stretched and bending vibration from surface adsorbed water or surface hydroxyl groups. ${ }^{36,37}$ The peak at $623 \mathrm{~cm}^{-1}$ corresponded to the $\mathrm{Cu}-\mathrm{O}$ stretching vibration..$^{38,39}$ The peak at $1115 \mathrm{~cm}^{-1}$ was attributed to the $\mathrm{S}-\mathrm{O}$ stretching vibrations in CuVOS. ${ }^{\mathbf{4 0 , 4 1}}$ The existence of the peak around $549 \mathrm{~cm}^{-1}$ also indicated the presence of $\mathrm{Cu}-\mathrm{S}$ stretching vibration. ${ }^{42}$

\subsection{UV-Vis absorption spectra}

Fig. 6a and b show the UV-Vis reflection and absorption spectroscopy of the CuOS and CuVOS, respectively. From the UV-Vis absorption spectra, the direct band gap was calculated with the equation as follows: $(\alpha h \nu)^{2}=k\left(h \nu-E_{\mathrm{g}}\right) \cdot{ }^{43} \mathrm{Fig}$. 6c indicates the $(\alpha h \nu)^{2}-h \nu$ curves of CuVOS and CuOS catalysts. The $E_{\mathrm{g}}$ values were to be 1.6-1.8 eV for CuVOS-1, 2, 3, 4, and $\sim 2.0 \mathrm{eV}$ for CuOS. As it is compared from CuOS, the band gap of CuVOS-1, 2, 3, 4 had smaller $E_{\mathrm{g}}$ values. The monocrystalline $\mathrm{CuO}$ of $E_{\mathrm{g}}=1.2-$ $1.4 \mathrm{eV}, \mathrm{Cu}_{2} \mathrm{O}$ of $2.0-2.2 \mathrm{eV}, \mathrm{Cu}_{2} \mathrm{~S}$ of $1.2-1.25 \mathrm{eV}, \mathrm{CuS}$ of 2.15$2.36 \mathrm{eV}$ are known. The band gaps of the samples further indicate that $\mathrm{CuVOS}$ is a bimetal oxysulfide solid solution.

\subsection{Catalytic reduction of 4-nitrophenol}

Fig. 7a and b show the control reduction of 4-NP by CuVOS catalysts. As is it observed from the Fig. 7a, the 4-NP solution was not changed in the presence of CuVOS catalyst. However, the addition of $\mathrm{NaBH}_{4}$ in the 4-NP solutions changed the absorption peak of the 4-NP from $317 \mathrm{~nm}$ to $400 \mathrm{~nm}$ (Fig. 7b). The shift of the absorption peak in the presence of $\mathrm{NaBH}_{4}$ reagent indicates the formation of 4-NP ion, which is also accompanied by a light yellow to deep yellow color change. ${ }^{24}$ Moreover, Fig. 7c shows the reduction reaction of 4-NP solution with the CuVOS-3 catalyst in the presence of $\mathrm{NaBH}_{4}$. It is indicated that the absorption peak at $400 \mathrm{~nm}$ rapidly decreased and subsequently a new peaks appeared at $300 \mathrm{~nm}$ which belonged to 4 -AP. ${ }^{6,24}$ Fig. 7d shows the percentage of the 4-NP reduction reaction over the CuOS and CuVOS prepared with different amounts of $\mathrm{N}_{2} \mathrm{H}_{4}$. As indicated from the Fig. 7d, the reduction of 4-NP with CuVOS in the presence of $\mathrm{NaBH}_{4}$ was faster. However, the reduction of 4-NP was insignificant in the presence of CuOS. The kinetic rates of reaction with $\mathrm{Cu}$ VOS catalyst prepared with different amounts of $\mathrm{N}_{2} \mathrm{H}_{4}$ followed the order:

Table 2 Comparison of the catalytic activity of various catalysts reported in literature for the reduction of 4- $\mathrm{NP}_{\text {by }} \mathrm{NaBH}_{4}$

\begin{tabular}{|c|c|c|c|c|c|}
\hline No. & Catalysts/amount & Time (s) & Kinetic rate constant, $k_{\text {app }}\left(\mathrm{s}^{-1}\right)$ & Ratio constant, $K\left(\mathrm{~s}^{-1} \mathrm{~g}^{-1}\right)$ & Ref. \\
\hline 1 & $\mathrm{Co}_{3} \mathrm{O}_{4} / 100 \mathrm{mg}$ & 120 & 0.013 & 0.13 & 45 \\
\hline 2 & NiPt-0.6\%/15.5 mg & 140 & 0.01882 & 1.2 & 46 \\
\hline 4 & $\mathrm{Cu}_{2} \mathrm{O}-\mathrm{Cu}-\mathrm{CuO} / 1 \mathrm{mg}$ & 180 & 0.0156 & 15.6 & 47 \\
\hline 5 & $\mathrm{SiO}_{2} @ \mathrm{Cu}_{x} \mathrm{O} @ \mathrm{TiO}_{2} / 10 \mathrm{mg}$ & 210 & 0.025 & 2.5 & 24 \\
\hline 6 & $\mathrm{CuOS} / 5 \mathrm{mg}$ & 300 & - & - & This work \\
\hline 9 & $\mathrm{Cu} V \mathrm{OS}-3 / 5 \mathrm{mg}$ & 120 & 0.041 & 8.1 & This work \\
\hline 10 & $\mathrm{Cu} V \mathrm{OS}-4 / 5 \mathrm{mg}$ & 180 & 0.027 & 5.4 & This work \\
\hline
\end{tabular}


CuVOS-3 > CuVOS-2 > CuVOS- $4>\mathrm{Cu} V O S-1>\mathrm{CuOS}$. This indicated that the CuVOS prepared with suitable amount of $\mathrm{N}_{2} \mathrm{H}_{4}$ will have an appropriate $n[\mathrm{Cu}(\mathrm{I}) / \mathrm{Cu}(\mathrm{II})]$ molar ratio and is expected to generate the anion vacancy due to the high $\mathrm{Cu}^{+}$in $\mathrm{Cu}^{2+} \mathrm{S}^{2-}$ covellite structure. Moreover, the addition of $\mathrm{N}_{2} \mathrm{H}_{4}$ also leads to the change the surface defect state of CuVOS in order to facilitate its interaction with 4-NP. The CuVOS with the suitable $n[\mathrm{Cu}(\mathrm{I}) / \mathrm{Cu}(\mathrm{II})]$ molar ratio can also transfer the electron between the $\mathrm{Cu}(\mathrm{I})$ and $\mathrm{Cu}(\mathrm{II})$ species., , $^{\mathbf{4} 4}$

Moreover, the catalytic performances of our catalysts were also compared with other literature reports. As it is indicated in
Table 2, complete reduction of 4-NP was achieved by $5 \mathrm{mg}$ CuVOS-3 catalyst in the presence of $\mathrm{NaBH}_{4}$ within 2 min reaction time. Therefore, our catalysts prepared with facile method had comparable catalytic performance towards reduction of 4NP with reported literatures. Table 2 shows the comparison of the catalytic activity of various catalysts reported in literature with CuVOS.

Furthermore, the catalytic stability was also studied by using the CuVOS-3 catalyst and its performance is shown in the Fig. 7e. After the $5^{\text {th }}$ run, the CuVOS-3 had a very good reduction capability of 4-NP. In order to check the catalyst stability, the
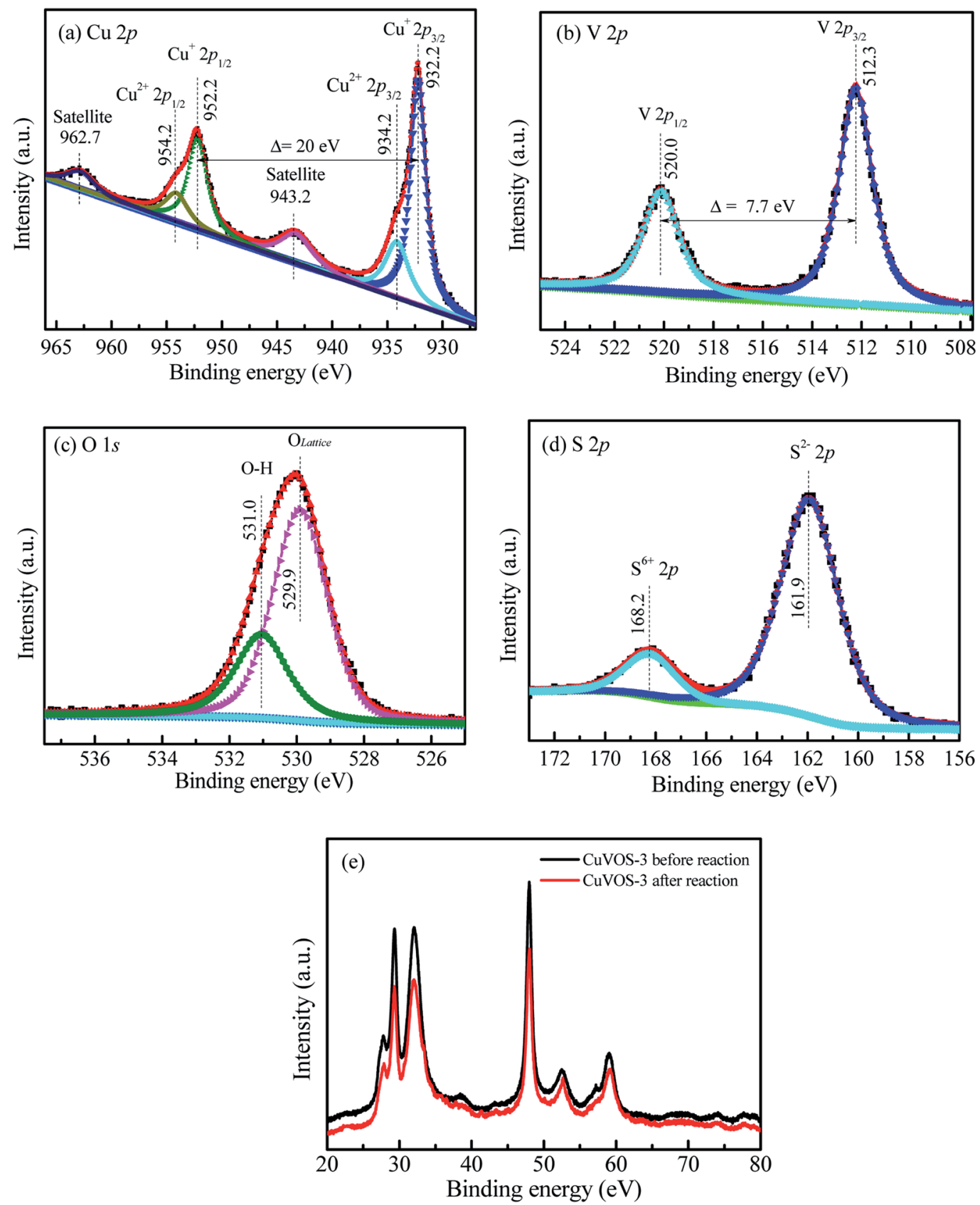

Fig. 8 High resolution (a) Cu 2p, (b) V 2p, (c) O 1s, and (d) S 2p XPS spectra of CuVOS-3 after reaction. (e) XRD diffraction patterns of CuVOS-3 for before and after reaction. 

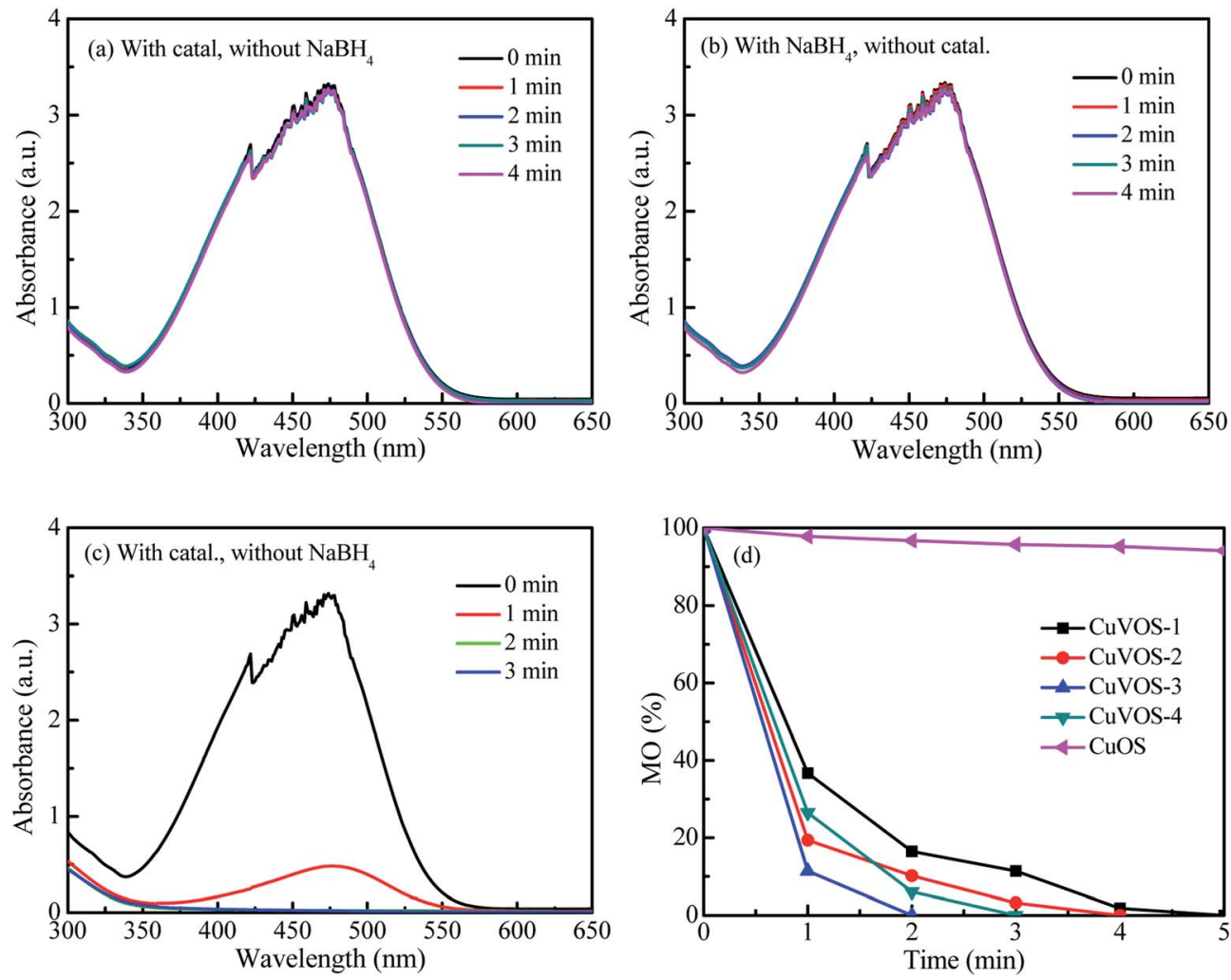

Fig. 9 (a) Reduction of $\mathrm{MO}$ by CuVOS-3 catalyst without $\mathrm{NaBH}_{4}$, (b) reduction of $\mathrm{MO}$ with $\mathrm{NaBH}_{4}$ without catalyst, (c) reduction of $\mathrm{MO}$ by CuVOS-3 catalyst with different $\mathrm{NaBH}_{4}$, (d) Reduction of $\mathrm{MO}$ with CuVOS series catalysts at different reaction times.
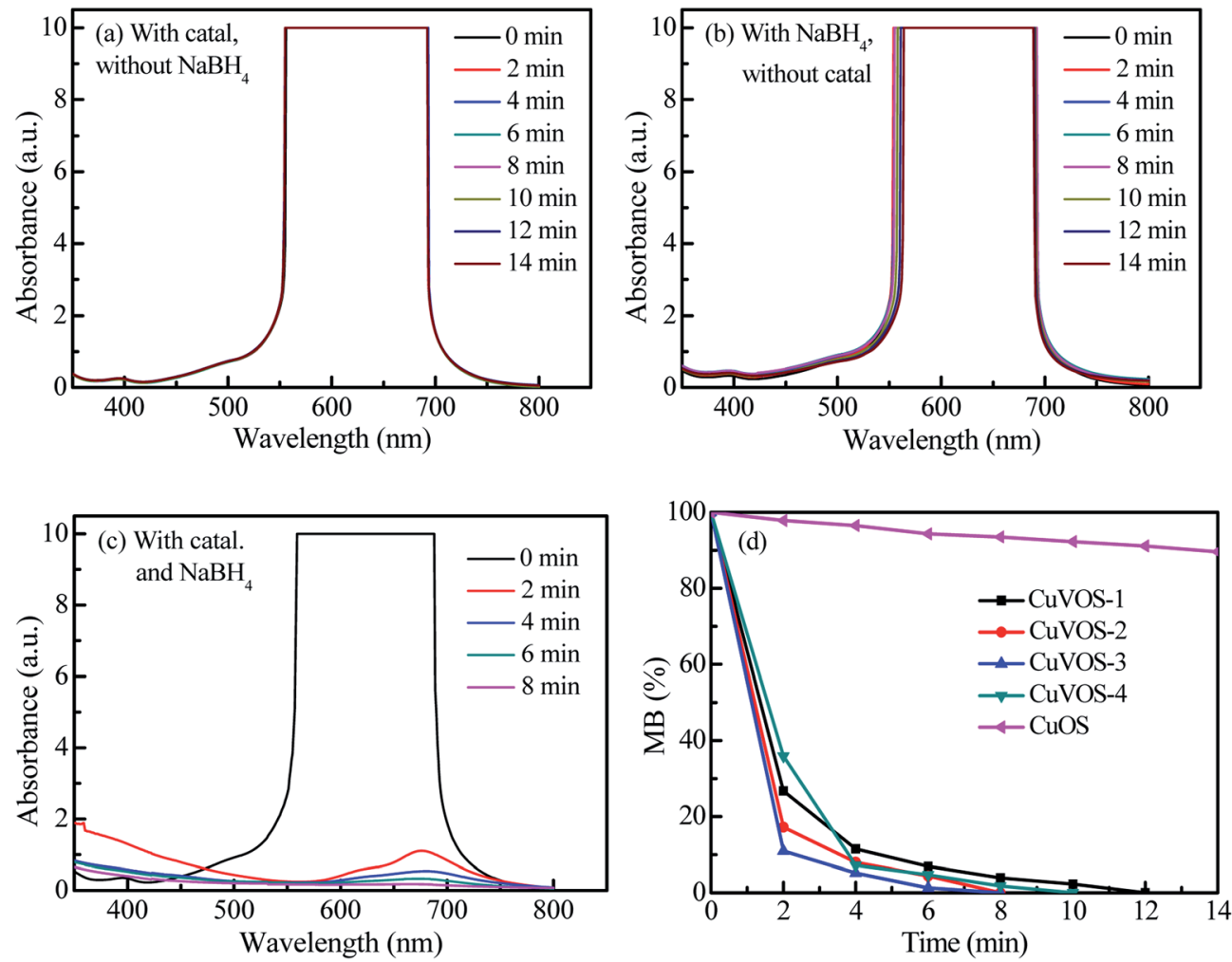

Fig. 10 (a) Reduction of $\mathrm{MB}$ with CuVOS-3 without $\mathrm{NaBH}_{4}$, (b) reduction of $\mathrm{MB}$ by $\mathrm{NaBH}_{4}$ without catalyst, (c) reduction of MB by CuVOS-3 catalyst with $\mathrm{NaBH}_{4}$, and (d) reduction of $\mathrm{MB}$ by CuVOS catalysts prepared at different $\mathrm{N}_{2} \mathrm{H}_{4}$ contents with $\mathrm{NaBH}_{4}$ under dark. 
XPS analysis was performed after reduction of 4-NP. Fig. 8a shows the high resolution $\mathrm{Cu} 2 \mathrm{p}$ XPS spectrum of CuVOS-3 after reduction reaction. The peaks located at $932.1 \mathrm{eV}$ and $952.1 \mathrm{eV}$ for $\mathrm{Cu} 2 \mathrm{p}_{3 / 2}$ and $\mathrm{Cu} 2 \mathrm{p}_{1 / 2}$, respectively, indicate the existence of $\mathrm{Cu}(\mathrm{I}) .{ }^{29}$ The $\mathrm{Cu}(\mathrm{II})$ oxidation state peaks of $\mathrm{Cu} 2 \mathrm{p}_{3 / 2}$ and $\mathrm{Cu} 2 \mathrm{p}_{1 / 2}$ were located at $934.1 \mathrm{eV}$ and $954.1 \mathrm{eV}$, respectively. ${ }^{30,31}$ According to the quantitative analysis by integrating the peak area, the $\mathrm{Cu}(\mathrm{I}) / \mathrm{Cu}$ (II) molar ratios of catalysts were calculated to be close to the CuVOS-3 catalyst before reaction. Fig. 8b shows the high resolution V 2p XPS spectrum of CuVOS-3 after reaction. The peaks of located at $512.0 \mathrm{eV}$ and $519.7 \mathrm{eV}$ were attributed to $\mathrm{V}$ $2 \mathrm{p}_{3 / 2}$ and $\mathrm{V} 2 \mathrm{p}_{1 / 2}$, respectively, which indicated the V(Iv) oxidation state. ${ }^{32,33}$ Fig. $8 \mathrm{c}$ shows the high resolution O 1s XPS spectrum of CuVOS-3 after reaction. The peak located at $532.2 \mathrm{eV}$ was contributed from hydroxyl oxygen, and at $530.1 \mathrm{eV}$ from lattice oxygen. Fig. 8d shows the high resolution $S 2 p$ XPS spectrum of CuVOS-3 after reaction. The $\mathrm{S} 2 \mathrm{p}$ peaks at $165.6 \mathrm{eV}$ and $171.9 \mathrm{eV}$ belonged to the $\mathrm{S}^{2-}$ and $\mathrm{S}^{6+}$, respectively. ${ }^{34,48}$ According to the quantitative analysis by integrating the peak area, the $\mathrm{S}^{6+} / \mathrm{S}^{2-}$ molar ratios of catalysts were calculated to be close to the CuVOS-3 catalyst before reaction as it is shown in Table 1. Furthermore, Fig. 8e shows the XRD diffraction patterns of CuVOS-3 before and after reaction. It can be seen that the peaks position of $\mathrm{Cu} V \mathrm{OS}-3$ before and after reaction are similar, but intensity of the peaks after reaction is little decreased. This result indicates that the catalyst is highly stable and can be used for multiple times.

\subsection{Reduction activity on organic dyes}

Fig. 9 shows the reduction of MO with CuVOS catalyst. The control experiments were shown in Fig. 9a and b. As observed in Fig. 9a and b, there were no reduction reactions by using only catalyst or only $\mathrm{NaBH}_{4}$. However, the complete reduction of MO within 2 min was taken place in the presence of both CuVOS-3 catalyst and $\mathrm{NaBH}_{4}$ (Fig. 9c). Moreover, Fig. 9d shows the pseudo first-order apparent reaction rate constant $\left(k_{\text {app }}\right)$ of MO reduction over CuVOS catalysts having the order of reaction as follows: CuVOS-3 $\left(k_{\mathrm{app}}=1.94 \mathrm{~min}^{-1}\right)>\operatorname{CuVOS}-4\left(k_{\mathrm{app}}=\right.$ $\left.1.40 \mathrm{~min}^{-1}\right)>\operatorname{Cu}$ OOS-2 $\left(k_{\text {app }}=1.07 \mathrm{~min}^{-1}\right)>\operatorname{CuVOS}-1\left(k_{\text {app }}=\right.$ $\left.0.70 \mathrm{~min}^{-1}\right)>\operatorname{CuOS}\left(k_{\text {app }}=0.01 \mathrm{~min}^{-1}\right)$. It is noted that the completed reduction of MO was achieved within as 2 minutes by CuVOS-3 catalyst, while CuOS only achieved for $8 \%$ in 10 minutes.

In order to evaluate the reduction performance of the CuVOS catalyst, the catalysts were also used to reduce $\mathrm{MB}$ and $\mathrm{RhB}$, and the results were shown in Fig. 10 and 11. The control experiments of $\mathrm{Cu}$ OOS catalysts for $\mathrm{MB}$ and $\mathrm{RhB}$ reduction are shown in Fig. 10a, b and 11a, b, respectively. Moreover, Fig. 10c and 11c indicate the reduction of $\mathrm{MB}$ and $\mathrm{RhB}$ dyes, respectively, by CuVOS-3 catalysts. The strongest peaks of MB at 560-700 nm was completely degraded in the presence of CuVOS-3 catalyst in 8 min, while CuOS degraded only less than 10\% (Fig. 10d). The pseudo first-order apparent reaction rate constant $\left(k_{\mathrm{app}}\right)$ of $\mathrm{MB}$ reduction over CuVOS is as follows: CuVOS-3 $\left(k_{\text {app }}=0.72 \mathrm{~min}^{-1}\right)$ $>\operatorname{CuVOS}-4\left(k_{\text {app }}=0.59 \mathrm{~min}^{-1}\right)>\operatorname{CuVOS}-2\left(k_{\text {app }}=0.48 \mathrm{~min}^{-1}\right)>$
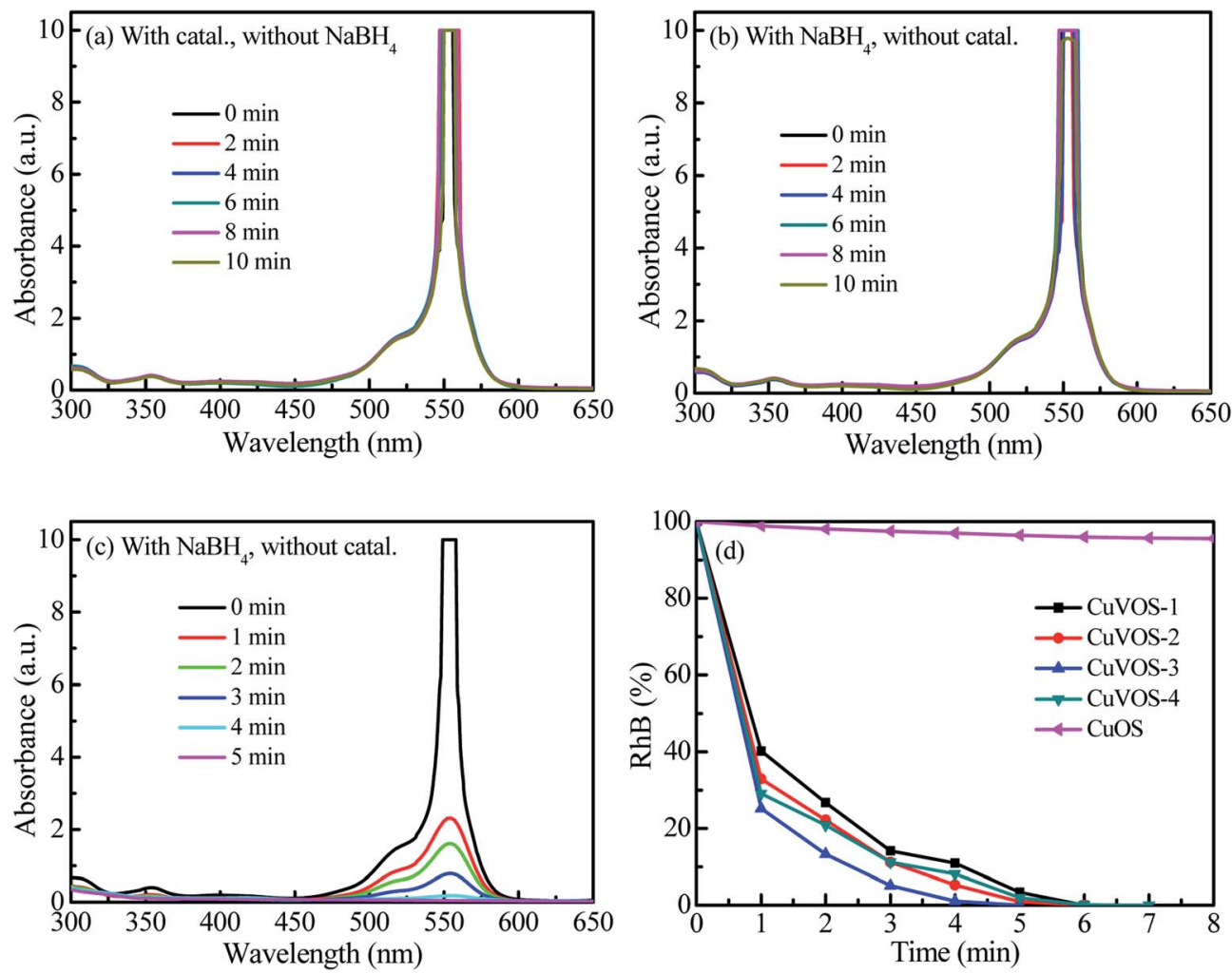

Fig. 11 (a) Reduction of $\mathrm{RhB}$ with CuVOS-3 catalyst without $\mathrm{NaBH}_{4}$, (b) reduction of $\mathrm{RhB}$ by $\mathrm{NaBH}_{4}$ without catalyst, (c) reduction of RhB by CuVOS-3 catalyst with $\mathrm{NaBH}_{4}$, and (d) reduction of RhB by CuVOS catalyst prepared at different $\mathrm{N}_{2} \mathrm{H}_{4}$ contents with $\mathrm{NaBH}_{4}$ under dark. 


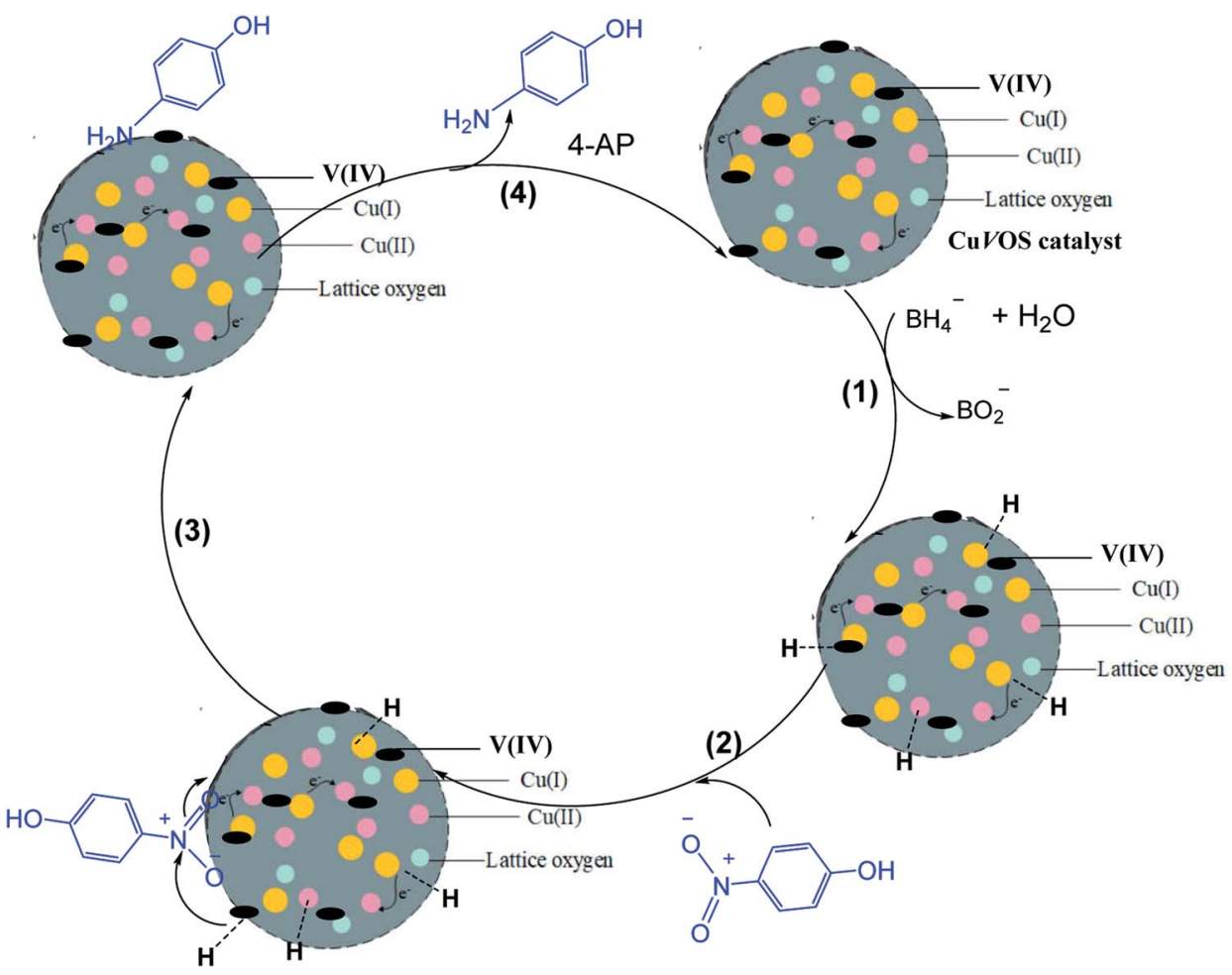

Fig. 12 The schematic reaction of 4-NP in presence of the CuVOS catalyst.

CuVOS-1 $\left(k_{\text {app }}=0.29 \min ^{-1}\right)>\operatorname{CuOS}\left(k_{\text {app }}=0.01 \mathrm{~min}^{-1}\right)$. Similar to $\mathrm{MB}$, the pseudo first-order apparent reaction rate constant $\left(k_{\text {app }}\right)$ of $\mathrm{RhB}$ reduction over CuVOS is also calculated as follows: CuVOS-3 $\left(k_{\text {app }}=0.93 \mathrm{~min}^{-1}\right)>\operatorname{CuVOS}-2\left(k_{\text {app }}=\right.$ $\left.0.78 \mathrm{~min}^{-1}\right)>\operatorname{Cu} V O S-4\left(k_{\mathrm{app}}=0.74 \mathrm{~min}^{-1}\right)>\operatorname{Cu} V O S-1\left(k_{\mathrm{app}}=\right.$ $\left.0.51 \mathrm{~min}^{-1}\right)>\operatorname{CuOS}\left(k_{\text {app }}=0.004 \mathrm{~min}^{-1}\right)$. Based on the above analyses, the reduction capability of CuVOS on pollutants is as follow: $\mathrm{MO}>\mathrm{RhB}>\mathrm{MB}$. It is further demonstrated that the bimetallic oxysulfide CuVOS catalyst has great prospects in industrial applications for wastewater treatment.

\subsection{The proposed reduction reaction mechanism}

Fig. 12 shows a possible reaction mechanism for the catalytic reduction of 4-NP by CuVOS catalyst in the presence of $\mathrm{NaBH}_{4}$ as a reducing agent. When $\mathrm{NaBH}_{4}$ is dissociated, the $\mathrm{BH}_{4}{ }^{-}$ion is released and attached on the surface of the catalyst (step 1). Then, the hydride ion is bonded covalently with the CuVOS (step 2). Simultaneously, the adsorption of nitro groups of 4-NP, will took place on the surface of the catalyst as it is shown in step 3 . The strong interactions between adsorbed 4-NP and covalently bonded hydrogen atoms will occur. Then, the adsorbed nitro groups will react with the hydride ion and reduction took place through the transfer of electron from donor $\mathrm{BH}_{4}{ }^{-}$to the acceptor 4-NP and lead to desorption of 4-AP product. ${ }^{49}$ In addition, $\mathrm{Cu}(\mathrm{I})$ and $\mathrm{Cu}(\mathrm{II})$ in the $\mathrm{Cu}$ VOS catalyst can transfer the electron and to accelerate the reduction reaction. ${ }^{50,51}$ Moreover, the $\mathrm{V}$ (IV) atom will also accept the electrons and transfer for the reduction purpose. Fig. 12 shows the mechanism of 4-NP reduction catalyzed by $\mathrm{CuVOS}$.

\section{Conclusions}

A copper-vanadium bimetallic oxysulfide CuVOS catalyst was successfully synthesized by facile method and had excellent reducing activities for $4-\mathrm{NP}, \mathrm{MO}, \mathrm{MB}$, and $\mathrm{RhB}$. It showed that, a $100 \mathrm{~mL}$ of $4-\mathrm{NP}(20 \mathrm{ppm})$ solution was completely reduced in the presence of $5 \mathrm{mg}$ of $\mathrm{CuVOS}-3$. Moreover, the complete reduction of $100 \mathrm{~mL}$ of $\mathrm{MO}, \mathrm{RhB}$, and $\mathrm{MB}$ solutions (100 ppm) were also achieved within $2 \mathrm{~min}, 6 \mathrm{~min}$, and $5 \mathrm{~min}$, respectively,

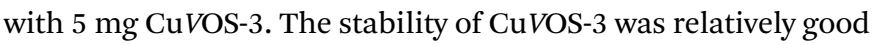
after using repeatedly for the reduction of 4-NP. Hence, the $\mathrm{Cu} V O S$ prepared in the presence of optimum amount of $\mathrm{N}_{2} \mathrm{H}_{4}$ is an efficient catalyst for reducing 4-NP and other organic dyes and may have a great potential for industrial application.

\section{Conflicts of interest}

There are no conflicts to declare.

\section{Acknowledgements}

This work was supported by the National Natural Science Foundation of China under the grant No. 31000269, the Strait Postdoctoral Program under the grant No. 1323H0005, and the China Postdoctoral Program under the grant No. 2018M632562.

\section{References}

1 A. K. Abay, X. Chen and D.-H. Kuo, New J. Chem., 2017, 41, 5628-5638. 
2 X. Yang, H. Zhong, Y. Zhu, H. Jiang, J. Shen, J. Huang and C. Li, J. Mater. Chem. A, 2014, 2, 9040.

3 K. He, G. Chen, G. Zeng, A. Chen, Z. Huang, J. Shi, T. Huang, M. Peng and L. Hu, Appl. Catal., B, 2018, 228, 19-28.

4 B. K. Ghosh and N. N. Ghosh, J. Nanosci. Nanotechnol., 2018, 18, 3735-3758.

5 T. Aditya, A. Pal and T. Pal, Chem. Commun., 2015, 51, 94109431.

6 O. A. Zelekew and D.-H. Kuo, RSC Adv., 2017, 7, 4353-4362.

7 M. J. Ahmed and M. Ahmaruzzaman, J. Environ. Manage., 2015, 163, 163-173.

8 X. Chen, D.-H. Kuo, J. Zhang, Q. Lu and J. Lin, J. Mol. Liq., 2019, 275, 204-214.

9 F. Liu, Y. H. Leung, A. B. Djurišić, A. M. C. Ng and W. K. Chan, J. Phys. Chem. C, 2013, 117, 12218-12228.

10 W. Jiang, X. Wang, Z. Wu, X. Yue, S. Yuan, H. Lu and B. Liang, Ind. Eng. Chem. Res., 2015, 54, 832-841.

11 S. Du, Z. Liao, Z. Qin, F. Zuo and X. Li, Catal. Commun., 2015, 72, 86-90.

12 R. Patel and S. Suresh, J. Hazard. Mater., 2006, 137, 17291741.

13 Y. Xie, B. Yan, H. Xu, J. Chen, Q. Liu, Y. Deng and H. Zeng, ACS Appl. Mater. Interfaces, 2014, 6, 8845-8852.

14 M. T. Yagub, T. K. Sen, S. Afroze and H. M. Ang, Adv. Colloid Interface Sci., 2014, 209, 172-184.

15 J. Liu, L. Han, H. Ma, H. Tian, J. Yang, Q. Zhang, B. J. Seligmann, S. Wang and J. Liu, Sci. Bull., 2016, 61, 1543-1550.

16 H. Lachheb, E. Puzenat, A. Houas, M. Ksibi, E. Elaloui, C. Guillard and J.-M. Herrmann, Appl. Catal., B, 2002, 39, 75-90.

17 C. Y. Teh, P. M. Budiman, K. P. Y. Shak and T. Y. Wu, Ind. Eng. Chem. Res., 2016, 55, 4363-4389.

18 B. R. Ganapuram, M. Alle, R. Dadigala, A. Dasari, V. Maragoni and V. Guttena, Int. Nano Lett., 2015, 5, 215-222.

$19 \mathrm{X}$. Chen, H. Sun, J. Zhang, O. Ahmed Zelekew, D. Lu, D.-H. Kuo and J. Lin, Appl. Catal., B, 2019, 252, 152-163.

20 B. Sun, H. Li, X. Li, X. Liu, C. Zhang, H. Xu and X. S. Zhao, Ind. Eng. Chem. Res., 2018, 57, 14011-14021.

21 X. Liu, D. Xu, D. Zhang, G. Zhang and L. Zhang, Appl. Catal., $B, 2016,186,193-203$.

22 B. Zhao, G. Mele, I. Pio, J. Li, L. Palmisano and G. Vasapollo, J. Hazard. Mater., 2010, 176, 569-574.

23 O. Ahmed Zelekew and D.-H. Kuo, Phys. Chem. Chem. Phys., 2016, 18, 4405-4414.

24 O. A. Zelekew and D.-H. Kuo, Appl. Surf. Sci., 2017, 393, 110118.

25 A. Elfiad, F. Galli, A. Djadoun, M. Sennour, S. Chegrouche, L. Meddour-Boukhobza and D. C. Boffito, Mater. Sci. Eng., B, 2018, 229, 126-134.
26 M. Ajmal, S. Demirci, M. Siddiq, N. Aktas and N. Sahiner, New J. Chem., 2016, 40, 1485-1496.

27 L. Ai, C. Zeng and Q. Wang, Catal. Commun., 2011, 14, 68-73.

28 H. Abdullah, D.-H. Kuo and X. Chen, Int. J. Hydrogen Energy, 2017, 42, 5638-5648.

29 N. Pauly, S. Tougaard and F. Yubero, Surf. Sci., 2014, 620, 1722.

30 S. Poulston, P. M. Parlett, P. Stone and M. Bowker, Surf. Interface Anal., 1996, 24, 811-820.

31 H. Qiu, S. Zhang, B. Pan, W. Zhang and L. Lv, J. Colloid Interface Sci., 2012, 366, 37-43.

32 J. Mendialdua, R. Casanova and Y. Barbaux, J. Electron Spectrosc. Relat. Phenom., 1995, 71, 249-261.

33 J. P. Holgado, G. Munuera, J. P. Espinós and A. R. GonzálezElipe, Appl. Surf. Sci., 2000, 158, 164-171.

34 S. Liu and X. Chen, J. Hazard. Mater., 2008, 152, 48-55.

35 H. Yuan, X. Ma and Z. Xu, Sci. China: Chem., 2011, 54, 257262.

36 X. Chen, H. Sun, J. Zhang, Y. Guo and D.-H. Kuo, J. Mol. Liq., 2019, 273, 50-57.

37 W. Zhang, Y. Shen, J. Zhang, H. Bi, S. Zhao, P. Zhou, C. Han, D. Wei and N. Cheng, Appl. Surf. Sci., 2019, 470, 581-590.

38 D. Gupta, S. R. Meher, N. Illyaskutty and Z. C. Alex, J. Alloys Compd., 2018, 743, 737-745.

39 S. Kumar, A. K. Ojha, D. Bhorolua, J. Das, A. Kumar and A. Hazarika, Phys. B, 2019, 558, 74-81.

40 D. Ma, Y. Xin, M. Gao and J. Wu, Appl. Catal., B, 2014, 147, 49-57.

41 L. G. Devi and R. Kavitha, Mater. Chem. Phys., 2014, 143, 1300-1308.

42 L. Z. Pei, J. F. Wang, X. X. Tao, S. B. Wang, Y. P. Dong, C. G. Fan and Q.-F. Zhang, Mater. Charact., 2011, 62, 354359.

43 C. Xu, S. Peng, C. Tan, H. Ang, H. Tan, H. Zhang and Q. Yan, J. Mater. Chem. A, 2014, 2, 5597-5601.

44 X. Chen and D.-H. Kuo, ACS Sustainable Chem. Eng., 2017, 5, 4133-4143.

45 T. R. Mandlimath and B. Gopal, J. Mol. Catal. A: Chem., 2011, 350, 9-15.

46 H. Shang, K. Pan, L. Zhang, B. Zhang and X. Xiang, Nanomaterials, 2016, 6, 103.

47 A. K. Sasmal, S. Dutta and T. Pal, Dalton Trans., 2016, 45, 3139-3150.

48 A. Galtayries and J.-P. Bonnelle, Surf. Interface Anal., 1995, 23, 171-179.

49 M. Tian, X. Cui, C. Dong and Z. Dong, Appl. Surf. Sci., 2016, 390, 100-106.

50 W. Lin and H. Frei, J. Am. Chem. Soc., 2005, 127, 1610-1611. 51 X. Chen, D.-H. Kuo, A. D. Saragih, Z.-Y. Wu, H. Abdullah and J. Lin, Chem. Eng. Sci., 2019, 194, 105-115. 